\title{
THE CHALCIDOID PARASITES OF THE COMMON HOUSE OR TYPHOID FLY (MUSCA DOMESTICA LINN.) AND ITS ALLIES. ${ }^{1}$
}

\section{iII. Description of a New North American Genus and Spe- cies of the Family Pteromalidae from Illinois, Parasitic on Musca domestica Linn., with Biological Notes.}

\section{By A. A. Girault and George Ethelbert Sanders,}

The University of Illinois.

The type species of this new and important genus of the pteromaline tribe Eutelini, was in point of numbers, third among the chalcidoid parasites reared by us during the investigations of the common house fly, during the latter part of the season of 1908, it being less numerous than species of Spalangia and the parasite Nasonia brevicornis Ashm. Unlike the latter, however, it was not reared independently or from a number of hosts, but nearly always occurred in connection with some one of the species of Spalangia and we were inclined to believe, though the evidence was lacking, that it usually attacked that genus, and hence is a secondary parasite of the typhoid fly, though its rôle may also be that of a primary parasite. A fact which contributed to our belief of its secondary rôle is the general likeness which it exhibits to Spalangia, a not uncommon thing between host and parasite or host and inquiline, though by no means the rule. But we have no evidence whatever to show that this is the case and are forced to the conclusion that the type species of the genus is a primary parasite in every sense.

In this third paper of this series, the genus is described and considered in detail and such biological facts as we were able to observe concerning it are also given. This genus, Spalangia and Pachycrepoideus dubius Ashm., already considered, are the principal primary parasites of the house fly, the species of Spalangia being the most numerous and common of the three genera. They will be considered in a paper to follow.

\footnotetext{
${ }^{1}$ Continued from Vol. XVII., p. 117.
} 


\section{Family Pteromalidae.}

\section{Subfamily Pteromalinae.}

Tribe Eutelini.

Muscidifurax gen. nov.

Type: $M$. raptor sp. nov.

Female. Normal in stature and aspect for the tribe. The general aspect of Tritneptis Girault, 1908, and of Colopisthia suborbicularis Prov. (Ashm.); moderate in size, the head rounded and prominent; submetallic, black.

Head (cephalic aspect) subcircular, moderate in size, the line of the vertex, however, somewhat flattened, slightly bi-lobed, the facial (mesal) impression containing the scapes distinct, moderately deep, but gentle, moderately defined and narrow, its lateral margins obtuse, the scrobes subobsolete dorsad, distinct near the bulbs, the latter separated; face broad, the clypeus sub-hemispherical, its surface not impressed below the face, but with close, fine, longitudinal, converging striæ, its sutures obsolete, its apical (ventral) margin truncate but laterad, on each side of the comparatively broad entire mesal portion of the margin near the lateral termination of the sclerite is a small subacute notch or incision; (lateral aspect) head distinctly bulged or convex below (ventrad) its middle, forming in the cephalic aspect, a rounded, convex facial prominence just ventrad of the insertion of the antennæ; head widest just ventrad of the ventral ends of the eyes and then ventrad of the insertion of the antennæ obliquely truncate (cephalo-caudad), the line of the face sloping gently from the vertex to the antennal insertions and then abruptly, obtusely changing angle and nearly truncately cut off; obovate; eyes elliptical-ovate, about a fourth longer than the genæ, practically naked, but bearing sparse, very minute, erect hairs; head with no acute margins; genal sulcus obsolete. (Dorsal aspect) head somewhat wider than the greatest width of the thorax, about three times wider than long at the vertex, the latter slightly narrowed at the meson, but rounded and slightly convex at its apex at the ocelli, the occipital margin concave, narrowly rounded; the cephalic margin of the vertex obscure, subacute; the cephalic ocelli circular, larger than the ovate lateral ones, all in a flat or obtuse triangle in the center of the vertex, distant from the eyes, the lateral ocelli about twice the distance from the eye margins on each side as they are from the cephalic ocellus, and a little less than that distance from each other than each is from the cephalic ocellus, the group near the obscure cephalic margin of the vertex; visible margin of the eyes convex, entire; eyes widely separated. Antennæ inserted about two-thirds of the way down to the clypeus, below the middle of the face and about on an imaginary line drawn between the ventral ends of the eyes, or slightly ventrad of it, the scapes long and slender,

1 Muscidae and furax, inclined to steal. 
diverging and dorsad extending to the apex of the vertex, the flagellum long and cylindrical, slightly thickening distad; antennæ 13-jointedscape, pedicel, 1 ring-joint, 7 -jointed funicle and 3 -jointed club; pedicel longer than the first funicle joint, the first and second joints of the funicle longest, the first joint the shorter of the two (Fig. 2). Mandibles 3- (left) and 4-dentate (right) (Fig. 1).

Pronotum distinct, narrow, transverse mesially, widening laterad, the lateral wings being cuneate, mesially not longer than a fourth of the length of the mesoscutum; thorax flatly convex; parapsidal furrows distinct, incomplete, inconspicuous, extending about one-half the length of the scutum, from the cephalic margin; axillæ widely separated; mesoscutum elliptical in outline, both the cephalic and caudal margin being broadly convex, the caudal margin nearly straight between the axillæ and im-

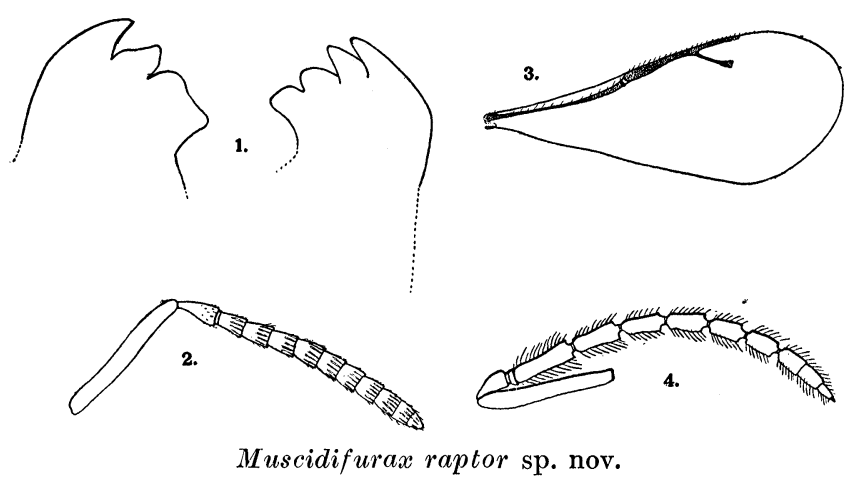

Fig. 1. Mandibles. Fig. 2. Antenna of female. Fig. 3. Fore wing of female (ciliation omitted). Fig. 4. Antenna of male. All enlarged; pubescence indicated only, not exact. Original.

pressed; scutellum with no transverse grooved line cephalad of the apex, but in its disk a few obscure, large punctures similar to those on the heads of many encyrtine genera, its apex broadly convex; mesopostscutellum narrow, following the outlines of the scutellum, its cephalic and caudal margins ridged or carinate; metathoracic spiracle moderately large, elliptical-oval, oblique in position and nearly its own length from either the mesopostscutellum or the lateral carina; median and lateral carinæ of the metathorax complete; median carina of the metathorax divided before base, each division proceeding latero-caudad to meet the lateral carinæ; the latter broken at caudal third; spiracular sulcus short, obscure. The whole of the head and thorax densely reticulated, amounting to punctation, the metathorax more coarse, punctate and rugose; abdomen finely, delicately reticulated, polished, the coxæ finely reticulated, nearly smooth. 
Abdomen sessile, (lateral aspect) conic-ovate, concave dorsad longitudinally, convex or ridged along the meson ventrad and pointed caudad, with the tip of the ovipositor exposed, not compressed, subdepressed, as long as the head and thorax combined; (dorsal aspect) abdomen ovate, ending in a sharp point, widest at about the apex of the third segment, the second segment longest, occupying a fourth of the surface, segment 3 next longest, excepting 7 and 8 , a third shorter, segments 4 and 5 subequal, slightly shorter than segment 3 ; the sutures between segments 2 and 3 obscure; segment 6 subequal to 3 but distinctly narrower, segment 7 triangular with the apex of the triangle caudad, at the meson three-fourths the length of segment 2 ; segment 8 pointed conical, as long as segment 6 , the point of the ovipositor protruding from it slightly; segments 7 and 8 pubescent. Abdomen somewhat variable in shape, sometimes slightly triangularly produced ventrad at base.

Legs normal, the anterior and posterior femora with their caudal margins convexed in the middle, but not conspicuously or abnormally so, the tibial spurs all single, the cephalic ones largest, curved, notched at the apex; caudal tibial spurs not half as long as the slender proximal tarsal joint, which is longest, the fourth caudal tarsal joint as usual, shortest, the third nearly as short as the fourth, the second about half as long as the first and longer than the fifth. Caudal coxæ largest, their lateral aspect flat, the intermediate coxæ by far smallest. The cephalic coxæ subconical.

Fore wings normal, widest at a point opposite the stigmal knob, usually ciliate in the disk, the apex rounded; submarginal vein slender, its whole length gently concavely curved, slightly enlarging as it nears the marginal vein, about a third longer than the latter; marginal vein broadened, clavate, its base twice the width of the postmarginal vein, gradually narrowing distad, dark, nearly twice the length of the postmarginal and stigmal veins; the latter two veins, slender, short, subequal in length, the postmarginal vein slightly longer, the angle between them about $45^{\circ}$; the stigmal vein straight, bearing a small ovate knob with an uncus proceeding from its cephalo-distal margin near apex. Marginal cilia absent, excepting along the venation and distad along the caudal margin where they disappear as the apex of the wing is neared; short. (Fig. 3). Posterior wings widest before their middle; the cephalic margin of the wing is nearly straight, obliquing distad; the caudal margin broadly convex, broadly emarginate towards base, sloping distad but the apex obtuse; discal cilia dense, but delicate and minute; marginal cilia moderate in length on the caudal margin. Venation usual; about 22 hooklets. Maxillary palpi 4-jointed, the last joint much the longest, cylindrical oval. Labial palpi 3-jointed.

Male-The same. Eyes smaller, about the length of the genæ, ovate; antennæ more slender, filiform, more noticeably hairy, pilose, more loosely jointed, the distal funicle joints subpedunculate; 14-jointed, with two ringjoints and a 4-jointed club; the funicle but 6 -jointed, the first funicle joint very long, cylindrical, narrowed in the middle, the joints shortening distad, 
the pedicel much shorter than the first funicle joint; apical joint spur-like (Fig. 4). Abdomen depressed, ovate, sessile, not as long as the thorax, the genitalia exserted in death; mandibles and other characters as in the female.

A genus closely allied to Eutelus Walker and Platymesopus Westwood, from both of which it is separated by the single ring-joint of the female antennæ, as well as more general characters.

\section{Host Relations of the Genus.}

The type and sole species of this genus, as our records given beyond will show, is an important primary parasite of the common house fly, of solitary habit and external, attacking the host in the puparium stage but not penetrating the body of the inclosed pupa, its larva obtaining nourishment through the body-wall of its host by means of absorption. Its host relations are therefore very similar to those of Spalangia - those species attacking Musca - in that it is mostly confined to a single host and is external and solitary in habit. But seemingly unlike the species of Spalangia, which we consider in another paper, this parasite also occasionally attacks other host genera, we having reared it rarely from the puparia of both the screw-worm fly, Chrysomyia macellaria (Fabr.) and also Phormia regina (Meig.); from the latter in the laboratory as well as in nature. Rarely, it was also reared from the larva of both of these flies.

\section{Distribution of the Genus.}

We have found this genus in what is practically a single locality in Illinois; in the two adjoining towns of Champaign and Urbana. In that locality it is common. Other portions of the state have not, of course, been explored in reference to it and we have no knowledge concerning its distribution in the United States.

\section{The Type Species of the Genus. \\ Muscidifurax raptor sp. nov.}

Female. Length variable; maximum length, $2.60 \mathrm{~mm}$; minimum length, $1.80 \mathrm{~mm}$.; average length, $2.24 \mathrm{~mm}$.; range, $0.80 \mathrm{~mm}$.; mode, $2.30 \mathrm{~mm}$.

General color black, with slight ænescence, subcorvinus; flagellum deep black, appearing slightly greyish from the pubescence; the abdomen with some brownish, at base ventrad on segment 3, a yellowish-brown spot on each side of the meson, often contiguous forming a transverse yellowish- 
brown band, and with traces of yellowish-brown dorsad at base of the second abdominal segment; the legs, excepting the concolorous black coxæ, and the scape fuscous, the femora dorsad and laterad variable, usually with blackish, especially in the caudal and cephalic femora; scape darker dorsad, pedicel and ring-joints with some yellowish; exposed portions of the mandibles black or dark fuscous; palpi dusky; tegulæ black; tarsi slightly paler, their distal joint black; wings subhyaline, the marginal vein conspicuous, black, especially proximad, the remaining venation dusky with some yellowish. Eyes dark garnet, with several discal black spots; ocelli pinkish, inconspicuous. Ventum concolorous, except as noted in the abdomen.

Pubescence of body moderately close, inconspicuous. Abdomen polished.

Flagellum moderately densely pubescent, the hairs short and closely applied; scape cylindrical, narrowing somewhat distad, equal in length, nearly, to the pedicel, ring-joint and 3 proximal funicle joints combined; pedicel long-obconic, its proximal end slightly curved, nearly thrice wider at its apex than at its base, not quite a third of the length of the scape and at least a fourth longer than the first funicle joint and its apex wider than that joint; ring-joint transverse, not as wide as the pedicel and about a fifth the length of the first funicle joint; first and second funicle joints subequal in length, both widening somewhat distad, the second somewhat wider than the first, each nearly a third longer than any of the next five funicle joints which are subequal in length, each, however, very slightly shorter than the one immediately preceding; the proximal club joint subequal in length and width to the seventh or distal funicle joint, the intermediate joint small, the apical joint small, obtusely conical, half the size of the preceding. Funicle joints $2-7$ subquadrate. Club as a whole ovate, not much, if any, wider than the funicle, not equal to the united lengths of the three distal funicle joints (joints 5,6 and 7 of funicle).

(From 194, specimens.)

Male. Length variable; $1.3-2.2 \mathrm{~mm}$; average, $1.82 \mathrm{~mm}$.

The same as the female, differing in the usual secondary sexual characters pointed out in the generic description, and in color as follows: The base of the abdomen in the dorsal aspect has a large conspicuous, rounded, honey-yellow spot, distinct to the naked eye, which is but slightly indicated in the female by the presence of some yellowish-brown in that region; in the same region ventrad, the area is larger than that in the female and rounded. The antennæ have an additional ring-joint, one joint less in the funicle and a very minute, additional fourth club joint, which are the unusual secondary structural features.

Flagellum filiform, pilose. Scape slender, a fourth longer than the pedicel, ring-joints and first funicle joint united; pedicel obconic, not as long as in the female, not by far a half the length of the proximal funicle joint, subequal in length to the distal (6th) funicle joint; ring-joints transverse, the second nearly twice the size of the first and darker in color; funicle joints all longer than wide, abruptly shortening distad; first funicle 
joint by far the longest, cylindrical, narrowed or constricted obtusely at the middle, over half the length of the scape, subequal to the club in length, somewhat shorter, with an indication of a petiole or peduncle at its apex and a third longer than the second funicle joint; the latter slightly constricted at proximal third, with a more distinct petiole, the third and fourth funicle joints subequal, each a fourth shorter than the second funicle joint; funicle joints 5 and 6 subequal, each a fourth shorter than either the third or fourth funicle joints, and each about half the length of the proximal funicle joint. Petiole or peduncle of joints 3, 4, 5, and 6 of the funicle distinct but not long; funicle joints 5 and 6 acute at their disto-lateral angles, the others less distinctly so; club moderately long, tapering to a point, distinctly shorter than the scape, its proximal joint somewhat shorter than the sixth funicle joint, but nearly as wide, its second joint slightly longer and as wille, its third joint conical, with a narrow truncate apex, not quite as long as the proximal joint, and the fourth distal joint minute, nipple-like, resembling a small conical spur and terminating in a seta.

(From 80 specimens.)

Types: Accession No. 40,250, Illinois State Laboratory of Natural History, Urbana, Illinois, 32 o's, 81 's, tagmounted.

Cotypes-Cotype No. 12,240, United States National Museum, Washington, D. C., 2 o's, 2 ' 's, tagmounted.

Viewed with a hand-lens, the female is uniformly glossy black with a conic-ovate, smoother abdomen which projects to the tip of the wings, marked ventrad near base with brownish-yellow, the wings hyaline with brownish-black marginal, postmarginal and stigmal veins, the latter distinctly tapering from the thicker base to apex; the legs, excepting black shining coxæ, brownish-yellow marked indistinctly with darker, the lateral aspect of the posterior femora dark; the antennæ black with the scape dark brownish. Eyes and ocelli dark garnet, the former with a discal blackish spot, not distinct; the pubescence indistinct on antennæ and body, giving the former an indistinct greyish appearance in direct light. The sculpture of head and thorax appears distinctly as a very slight, uniform and delicate roughening. The antennal flagella are about as long as the thorax. The sculpture appears rougher along the surface of the metanotum.

The male appears the same as the female, excepting the shorter, flattened, depressed abdomen containing a moderately large, brownish-yellow spot in the middle near base, and the slenderer, loosely-jointed, softly hairy antennal flagella, the pilose pubescence of which is distinct and yellowish grey.

When viewed with the naked eye, the parasites look like black gnats with long bodies, indistinct brown-yellow legs and indistinct clear wings which are folded along the back in the usual position for the Pteromalidæ. They appear a third smaller in size than Pteromalus puparum (Linn.) for instance to the naked eye and the sexes cannot be certainly separated without enlargement. Through a lens, however, the antennal and abdominal characters previously mentioned, together with the exserted genitalia of the male, allow them to be distinguished with readiness. To some extent, to 
the naked eye, the species resembles some of the smaller species of Spalangia and more closely, Pachycrepoideus dubius Ashmead, but the bodies of the latter are noticeably shorter and more compact, the antennæ shorter and stouter.

Described from the following 324 specimens, all, with the exception of 50, now in the collection of the Illinois State Laboratory of Natural History and all reared from various house fly puparia, and those of two other Diptera, during the investigations of 1908 in the insectary of the office of the State Entomologist of Illinois at Urbana. Unless otherwise stated all of the specimens are mounted on tags.

(1) Eleven males of the parasite emerged singly on October 17, from 11 puparia of Musca domestica Linnæus which had been exposed in the insectary September 20 and 30; accession No. 40,231 $11 \delta^{7}$ 's. (2) On October 24 from the same lot of isolated puparia, there were removed $340^{\prime \prime}$ s, 83 o's; accession No. 40,250, 32 o's, 81 ''s (2 O's, 2 ''s - Cotype No. 12,240, U. S. N. M.). (3) 6 \%'s from the same lot April 25, 1909; accession No. 41,082, 6 ' 's. (4)

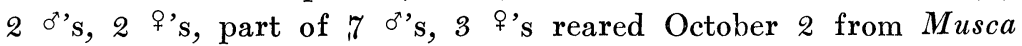
puparia (see 11), parents of the next two numbers; accession Nos.

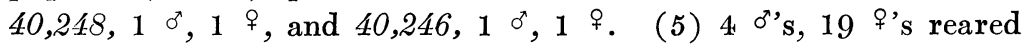
October 20 and November 7 from single $M$ usca puparia in confinement, progeny of the single pair of accession No. 40,248 (see preceding); accession Nos. 40,249, 3 o's, 10 \%'s and 40,269, $10^{\circ}, 9$ ' 's (6) $1 \sigma^{\pi}, 14$ 's reared October 20 to November 7 from 15 Musca puparia in confinement, progeny of the single pair of accession No. 40,246 (see 4) ; accession Nos. 40,247, $10^{\circ}, 7$ ' 's and 40,268, 7 ' 's. (7) $3 \sigma^{x}$ s reared September 26 from three Musca domestica puparia formed from maggots in horse manure and exposed to parasitism in the insectary September 8 to 11 ; accession No. 40,144, 3 ox's. $4{ }^{7}$ 's reared from four of the same host lot, September 27; accession No. 40,146, 4 o's. (9) $20^{*}$ 's reared from two of the same host lot September 28; accession No. 40,150, 2 o's. (10) 2 o's, 7 \%'s reared from nine of the same host lot September 30 ; accession No. 40,153, 2 o's, 7 \%'s. (11) 2 parthenogenetic females, reared from two puparia of lot 4 in preceding, parents of the following; accession Nos. 40,298 and 41,000, 2 's. (12) $20^{*}$ 's reared October 24 from two puparia of Phormia regina (Meigen), parthenogenetic 
progeny of the preceding number; accession Nos. 40,299 and 41,001, 2 o's. (13) 5 on's, 9 ' 's reared as in lot 4 ; discarded. (14) 3 $0^{\prime \prime}$, 12 's +42 reared October 4 with several Spalangia and $1 \sigma^{\prime}$ Pachycrepoideus dubius, from 57 Musca domestica puparia, exposed to infestation September 8-11; accession No. 40,1\%1, 3 0's, 12 ' 's. (15) 22 ' $' s+8$ reared from 30 of the same lot as 14 , the same species present in larger numbers, October 11 ; accession, No. 40,205, 22 ' s. (16) 1 \% collected in insectary around fly-breeding cages, September 10, parent of the next number; accession No. 39,965, 1 ․ (17) 7 ' 's reared in confinement from 7 puparia of Musca domestica October 1, progeny of the single female of the preceding; accession No. 40,169, 5 o's. (18) $0^{\circ}, 10^{\circ}$, each removed October 13 from single puparia of Phormia regina (Meigen) obtained from garbage at the city dumping-grounds, Champaign, September 23 ; accession No. 40,-

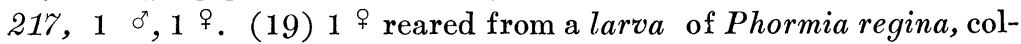
lected in garbage at the city dumping-grounds, Champaign, October 21 , and removed from the capsule containing the host larva on November 6 ; accession No. 40,258, 1 \%. (20) $20^{\prime \prime}$ s, 2 ' 's reared from four Musca domestica puparia September 29, parents of the next number; accession No. 40,242, $20^{x}$ 's, 2 's. (21) 2 ' 's reared in confinement from two puparia of Phormia regina (Meigen), October 19, progeny of the preceding; accession No. 40,243, 2 's. (22) 3 ơ's, 3 ' 's reared from six Musca domestica puparia, September 30, parents of the next; accession No. 40,244, 3 ox's, 3 '?'s. (23) 1 $\sigma, 1+$ reared in confinement from two puparia of Phormia regina (Meigen), October 19, progeny of the preceding; accession No. $40,245,10^{x}, 1 \stackrel{\circ}{\circ}$.

\section{Brological Notes.}

The brief duration of the investigations and the lack of time and opportunity prevented an extensive study of the life-history and biology of this parasite, and because of its lesser abundance and the somewhat greater difficulty experienced in handling it in confinement, not as much was learned concerning it as in the case of Nasonia brevicornis Ashm. It is more sensitive than the latter, has an apparently limited number of hosts and is solitary; yet, notwithstanding these, with time and opportunity, its biological history could be learned with ease in the laboratory, as the females are not 
at all adverse to ovipositing in confinement, as in the case of Spalangia and many other Chalcidoidea. But seemingly it is not as prolific and as general a parasite as is Nasonia.

We have not obtained positive data concerning the entire seasonal history of this parasite, but our observations indicate that it confines itself principally to the puparium stage of the house fly, following this single host throughout and hibernating in the host puparium as a larva, pupating and emerging early in the spring in time to attack the first host generation. The investigations concerning the house fly, and during which this parasite was discovered, did not commence until late in July, and the parasite did not appear, so far as we know, until the first week in September. From then on, until freezing weather commenced, it was comparatively common. It was reared from host puparia collected on September 23; and again, nearly a month later, from hosts collected on October 21, from a garbage heap then literally swarming with muscid maggots (Musca, Chrysomyia, Phormia); and from this last lot of puparia a few adults of the parasite had emerged by November 6 . On October 21 hibernation had probably commenced, for although adult Spalangia were found to be rather numerous in the soil around the muscid puparia at the garbage heap, neither raptor nor Nasonia brevicornis were seen. Further, hosts collected on November 14, 1908, from the same garbage heap, then covered with snow, when confined in the warm insectary, produced both adult raptor and Nasonia brevicornis which emerged about a month later, their development having evidently been hastened by the warmth. Facts such as these, strongly indicate hibernation in the host puparia and analogy would lead to the belief that this species has a winter history somewhat similar to that found in Nasonia brevicornis.

As briefly as possible, we summarize the few special experiments conducted with this parasite in the laboratory.

I. An adult female captured in the insectary around fly-breeding cages, September 13, was at once confined in a vial with a single puparium of Phormia regina; oviposition was observed within the next 24 hours, after which the parasite was released. No emergences followed. However, the host was examined in March, 1909, and found to contain fragments of the host pupa, the dead larva of this parasite, its body blackened but still soft up to May 20 follow- 
ing and its peculiar meconium. Hence, this parasite attacks Phormia regina in confinement.

II. a. On October 1, a pair of adults just reared from Musca puparia in horse manure were confined with 40 healthy puparia of the same host reared in confinement from maggots in garbage. Oviposition occurred and on October 20 following, four males and 19 females emerged as the offspring of the single female, making a total progeny of 23 .

$b$. Another pair from the same source and emerging at the same time were similarly confined with 30 fresh Musca puparia reared from the maggots in garbage. Reproduction occurred and on October 20, one male and 14 female parasites emerged as the total progeny of this pair.

Hence in confinement, single females were able to kill 23 and 15 hosts respectively, necessarily laying eggs to the extent of those amounts.

III. A single female parasite captured around the fly cages in the insectary, September 10, was confined in a glass vial with 11 healthy puparia of Musca domestica reared from maggots in horse manure; the parasite was confined with the hosts at $11.50 \mathrm{a} . \mathrm{m}$. the day of capture. As a result, on October 1, seven adult females had emerged, the total progeny; two of the remaining hosts died but examination disclosed no symptoms of parasitism; the other two produced $1 \sigma^{\circ}$ and $1 \%$ of the host on September 14 .

IV. Eleven females reared from 11 puparia of Musca domestica in horse manure September 29-30, and isolated at emergencehence virgin - were separately confined during September 30 with single puparia of Phormia regina. Reproduction occurred and in three cases single males resulted as the progeny of three of the virgin parents; adult hosts emerged in three cases and the remaining hosts died without showing symptoms of parasitism. Hence parthenogenesis occurs with this parasite, the unfertilized ova producing males. Here, there can be no doubt but that the females were unfertilized, mating within the puparium, obviously, being impossible.

V. a. September 29, two males and two females of the parasite reared from four puparia of Musca domestica on the same day, earlier in the morning, were confined with 15 puparia of Phormia regina. Oviposition was observed at 11.45 a. m., and doubtless 
occurred again. The resultant progeny proved to be two females from two of the puparia, emerging on the 19th of October.

$b$. Experiment similar to $a$. The following day three pairs of the parasite from the same source as in preceding were confined with 17 of the same host puparia, the resulting progeny proving to be one male and one female, emerging on October 19 following.

The experiments indicate fecundity, give the approximate duration of the life cycle and establish parthenogenesis, which, however, remains to be verified. They also show the readiness with which the puparia of Phormia are attacked in confinement.

\section{Habits and Biology in General.}

As the observations on all points of the life history and biology of this parasite were necessarily desultory, they can be presented in no other way than one seemingly fragmentary. For convenience and brevity they are summarized or collected under the following headings.

A. Nature of Parasitism. In the 309 (77 $0^{7}$ 's, 181 ' 's, 51 undetermined sex) cases of parasitism which were isolated in small gelatine capsules with special reference to the nature of parasitism, of which all but nine of the hosts ( $4 \delta^{x}, s, 5$ 's of the parasites) were Musca domestica, every one yielded but a single parasite, which shows beyond doubt that the species is solitary in habit, even when - rarely - attacking comparatively large hosts such as Chrysomyia and Phormia are. In a critical examination of the hosts, after the emergence of the parasite, it was found that in nearly all cases they were considerably reduced in bulk, but not noticeably in length, recognizable as pupæ, flattened, along the abdomen especially, hardened, shrunken and blackened - not collapsed or eaten away indicating that the larval parasite was attached to the external body-wall of the host, obtaining its nourishment by absorption through it. This indication has been proven to be a fact by several direct observations made on dissected hosts, known to be parasitized by this species, and the further fact established, namely, that the larval parasite has no particular choice as regards the portion of the body of the host to which it attaches itself or rather to which it becomes attached. The destruction of the host is more complete than with Nasonia, for some host pupæ are mere hollowed-out 
shells of the venter, but less so than is the case with Spalangia. In a few instances the hosts were mere fragments, but the great majority were as has been described.

After emergence of the adult parasite, an examination of the host puparium reveals at first the shrunken and blackened remains of the host pupa lying in its natural position along the floor of the puparium and attached to it, usually along the dorsum of the caudal portions of the abdomen, the yellowish pupal cast of the parasite and then caudad of the host remains, lying upon the floor of the puparium, free, the peculiar, round-angled, dark meconium of the parasite larva; or the latter may be attached to the host remains as in Spalangia, there resembling a dark clot. As this meconium is characteristic, and can be readily distinguished from that of Spalangia, and hence forms an available means of identity when others are absent, by way of description it may be stated that, to the naked eye, it resembles a small solid, black-brown bead, about thrice the size of a visible grain of sand, resembling somewhat a coarse grain of powder, but not as irregular or as angular, measuring actually about $.8 \mathrm{~mm}$., its general outline convex and dome-shaped, the bottom flat, and the convex upper side, with a concavity, groove or impression along or in its center or at one end; this impression is quite often segmented, and as it is known that it is formed by the abdomen of the parasitic pupa which rests in it, the segmented appearance is due to the impression made in the then soft meconium by the incisions of the abdominal segments of the larva; the place of this groove is variable, and it may be absent, tending to show that the pupa of the parasite was not attached to it in the usual way; the edges of the impression are quite often acute or sharpened ridges; from above the meconium's outline is circular, with some irregular angulation; rarely it is quite irregular. It is much smaller in diameter - at least by a half - than the meconium of Spalangia which is wider and flatter, lozenge- or discus-shaped, and hence the two are readily distinguished on comparison. So far as the evidence goes, the manner or nature of the parasitism does not differ for sex of the parasite nor for species of the host. However, in four authentic instances, instead of the puparium stadium being affected, it was the larval stadium. The hosts in these instances were Chrysomyia macellaria and Phormia regina and the parasites emerged from single, nearly full-grown larvæ isolated in capsules. 
B. Emergence of the Adult. When perfect and mature, having cast the pupal integument and rested, the adult parasite in order to obtain its freedom cuts a single rounded hole, measuring from 0.60 to $1.25 \mathrm{~mm}$. diameter, through the puparium with its mandibles. This exit-hole varies in position but is usually cephalad or caudad and in the dorsal aspect. Its edges are ragged or serrated. It does not vary for sex or host and is not unusual. In rare cases the parasite may make as many as four exit-holes, obviously because of its failure to accomplish its exit readily, as is normal. So far we know of no characteristics distinguishing the exit-holes of this parasite from those of Spalangia or Pachycrepoideus.

In regard to the time of emergence. The two sexes appear almost simultaneously, but our rearing records indicate an earlier appearance of the male as is usual. This sex, in a cycle lot of the same age, may appear from 24 to 36 hours earlier than the females, but not all together, the time given referring to the individuals of earliest appearance. The tendency in development is for a more rapid maturity of the males, taking the sex as a whole.

C. Oviposition; Number of Eggs Deposited. The facts concerning this habit are not well known and our observations are briefly stated. In one of the two cases observed, the host being Musca domestica Linnæus, the position of the female was essentially the same as with Nasonia brevicornis Ashm.; the ovipositor was inserted into one end of the host dorsad and 90 seconds were occupied in inserting or boring the ovipositor into the host, and the ovipositor was fully inserted for 105 seconds. In the other case observed (September $9,1908)$, the female stood lengthwise along the domestica puparium, along the median line dorsad, and inserted the ovipositor between two caudal segments; the antennæ and abdomen were moved slightly during the operation which lasted for seven minutes (6.15 a. m.); subsequently during the same day, this same female was observed making (apparent) oviposition into the same host, so that, though solitary, several ovipositions into single hosts may occur (confinement). As already stated, occasionally (rarely) the female may deposit into maggots, apparently when young, but it is a question how this occurs or under what conditions it could be accomplished.

Regarding the number of eggs deposited. But two observations of worth were made concerning this, as recorded on a previous page (experiment II.). Here two pairs of adults were given access to a 
number of healthy hosts, allowing some range in choice as regards the number of progeny. In case $a, 23$ progeny out of a "possible" 40 resulted, and in case $b, 15$ progeny out of a "possible" 30 resulted. As these pairs were fresh and had not reproduced previously, the results at least give us some notion concerning fecundity of the species.

D. Length of Life Cycle. We know nothing concerning the duration of the different stages, and but little concerning the duration of the cycle as a whole. What has been learned, was obtained by experiments conducted in confinement and is summarized in the following table:

Table I. Duration of the Life Cyole in Muscidifurax raptor, Several CyCles, 1908.

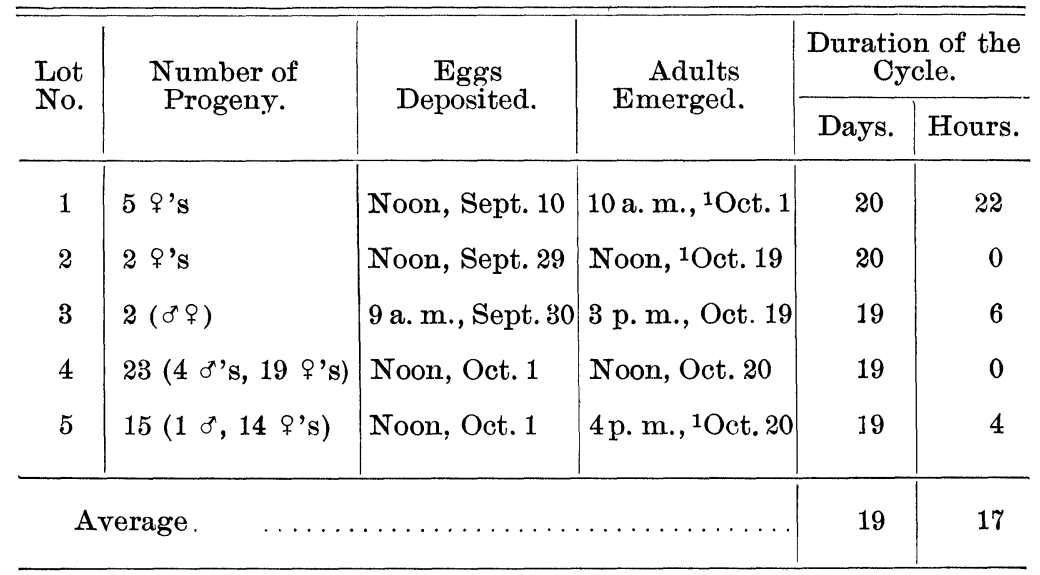

E. Proportion of the Sexes. Of the 288 reared specimens of this species concerning which the nature of the sex was recorded, there were 85 males and 203 females, or nearly two and a half times more females than males. This high preponderance of the females is unexpected in view of the natural history of the species, but parthenogenesis may account for it, following as it does no general law in the Hymenoptera. The figures given are for the whole total of the specimens reared by us, either artificially or from hosts obtained in nature and the proportions may be warped. Of the former those bred in confinement, hence artificially - totalling 52, but

1 Approximated to hours. 
nine were males and the remaining 43 females, the preponderance being still greater; of the 236 specimens obtained from hosts collected in nature, 77 were males and 159 females; the preponderance is much less than in the other class, being but as two is to one, and we are inclined to believe it to be the true condition.

\title{
THE FOOD OF CALLIGRAPHA BIGSBYANA, A CHRYS- OMELID BEETLE.
}

\author{
By Robert W. Hegner, \\ Ann Arbor, Mich.
}

All of the adult specimens and larvæ of Calligrapha bigsbyana secured for me, or that I myself have collected, have been found upon the long-leafed willow, Salix longifolia, and so far as I have been able to ascertain, they do not occur in nature upon any other species of plant. It was discovered several years ago that both adults and larvæ thrive equally well in the laboratory when fed upon leaves of Salix amygdaloides (Hegner, 1908). ${ }^{1}$ The following experiment was undertaken to learn if Salix longifolia is preferred.

Larvæ that had been fed in the laboratory on Salix amygdaloides pupated on July 2, and the adults emerged on July 14. On July 15 two males and two females were placed in a stender dish containing three leaves each of Salix longifolia and S. amygdaloides. The beetles crawled over the bottom, sides and top of the dish as well as over the leaves, and if they had preference for either sort of leaves they were given ample opportunity to show it. The leaves of $S$. amygdaloides were attacked as quickly as were those of S. longifolia, and as much of the former was eaten as of the latter. The experiment was continued for a month, fresh leaves of each species of willow being supplied to the beetles every day, but in no instance was a preference for either sort observed.

Beetles that are kept in stender dishes usually lay their eggs upon the leaves, but sometimes they fasten them to the sides or top of the dish. The two females used for this experiment chose one kind of leaf as often as the other upon which to lay their eggs. Why these beetles are found only on $S$. longifolia in nature, though they show no preference for it in the laboratory, is a question still unsolved.

\footnotetext{
1 Observations on the Breeding Habits of three Chrysomelid Beetles, Calligrapha bigsbyana, C. multipunctata, and C. lunata. Psyche, Vol. 15, pp. 21-24.
} 

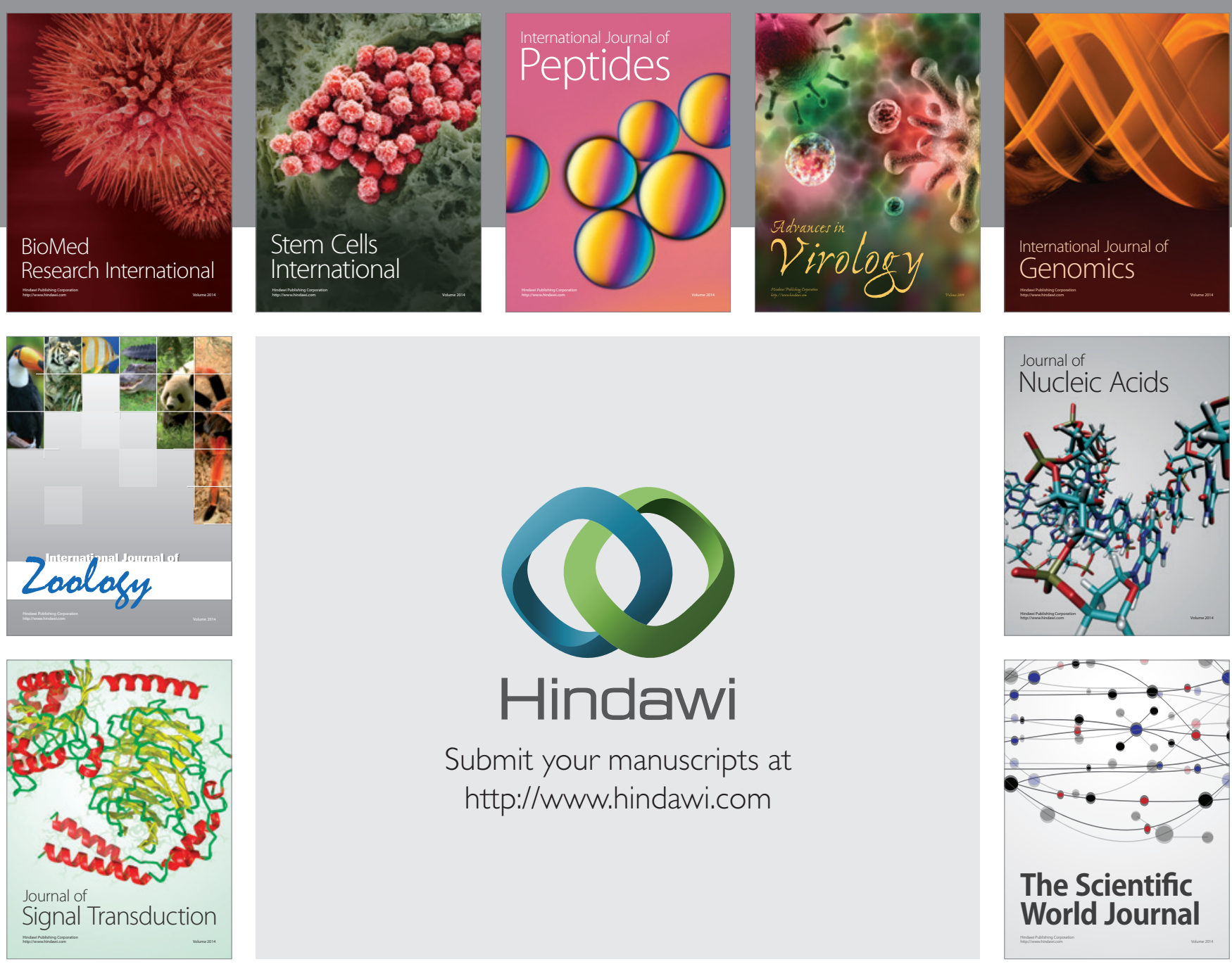

Submit your manuscripts at

http://www.hindawi.com
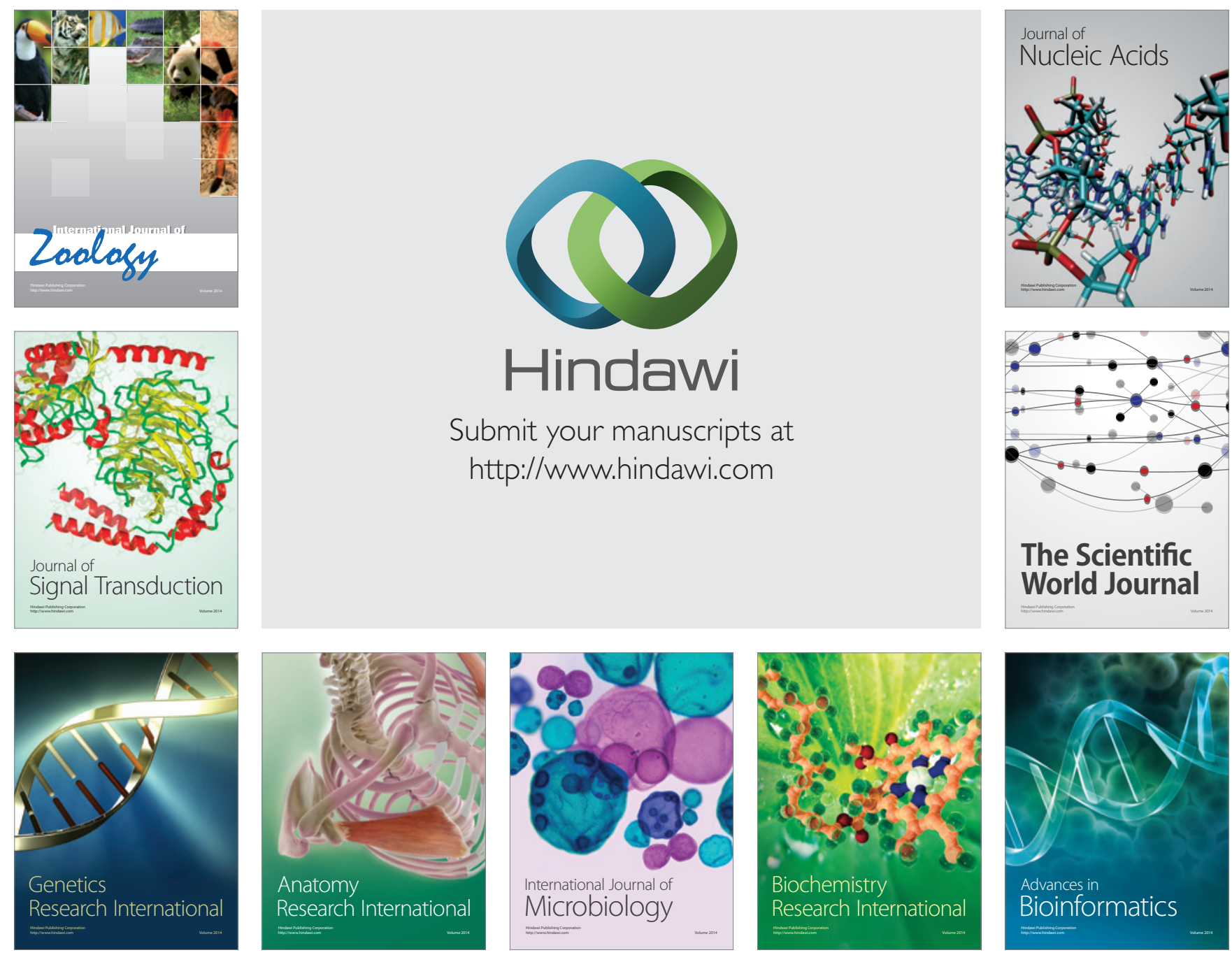

The Scientific World Journal
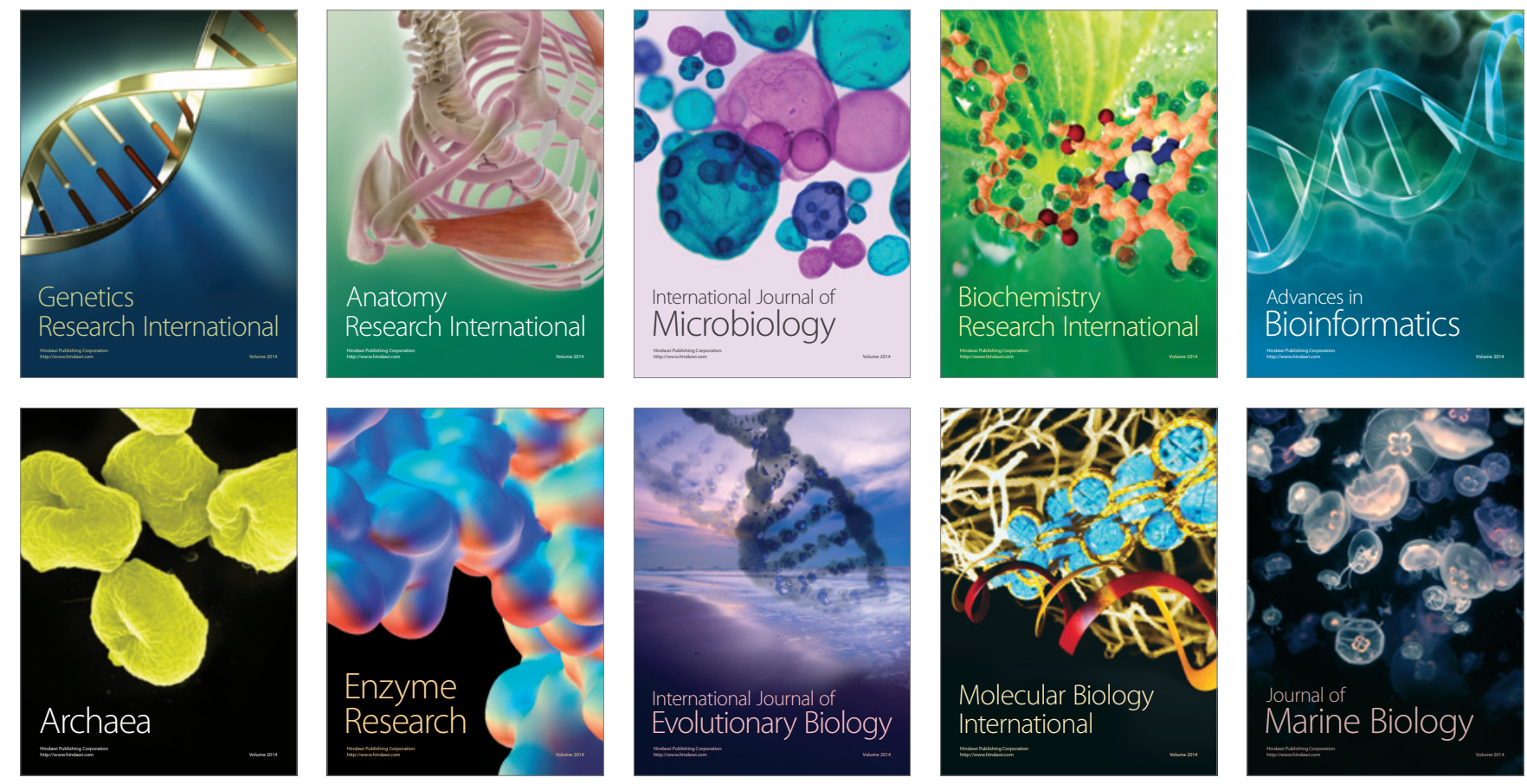